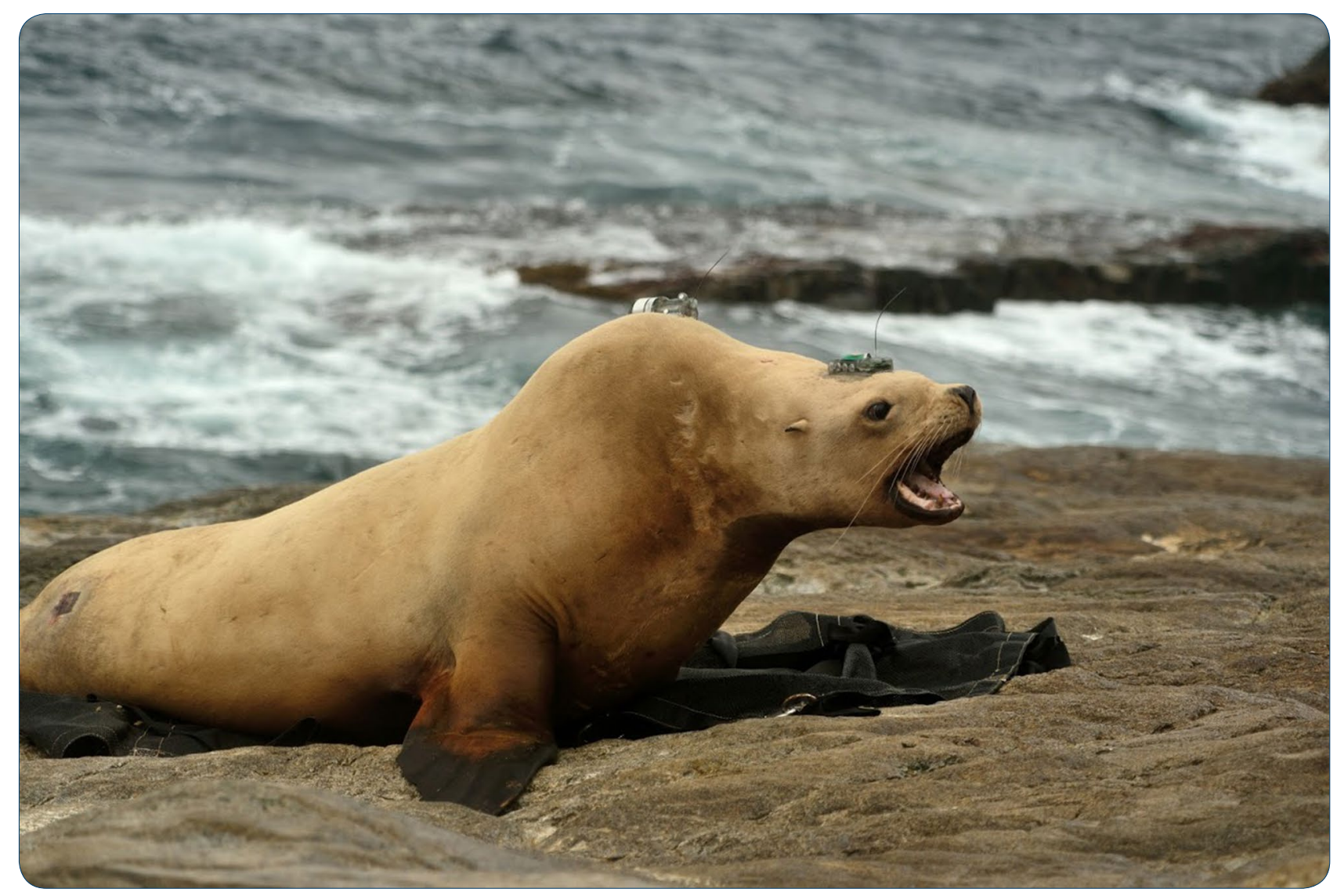

\title{
Development and field testing a satellite-linked fluorometer for marine vertebrates
}

Lander et al. 


\title{
Development and field testing a satellite-linked fluorometer for marine vertebrates
}

\author{
Michelle E. Lander ${ }^{1 *}$, Todd Lindstrom² ${ }^{2}$ Matthew Rutishauser ${ }^{2}$, Albert Franzheim² and Melinda Holland ${ }^{2}$
}

\begin{abstract}
Background: Understanding the responses of marine vertebrates to spatial and temporal variability of primary productivity is fundamental for their conservation and for predicting how they will be affected by climate change. Despite recent advances in biotelemetry, fluorometers have only recently been incorporated into larger transmitting systems. The purpose of this project was to incorporate a miniature fluorometer into a satellite-linked transmitter to provide measures of in situ phytoplankton fluorescence, which were used to calculate chlorophyll- $a$ (chl- $a$ ), a proxy for primary productivity. After evaluating the suitability of commercially available fluorometers, the ECO Puck ${ }^{\mathrm{TM}}$ (WET

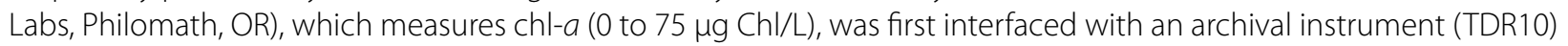
manufactured by Wildlife Computers (Redmond, WA, USA) to (1) determine if the interfaced prototype functioned properly, (2) examine data relative to the orientation of the optics, (3) monitor the behavior of tagged animals, and (4) collect a complete dive/sensor record to validate a data reduction routine established for Service Argos and verify performance of the Argos message generation.
\end{abstract}

Results: After laboratory and field trials indicated the interfaced archival prototype operated effectively and was robust to animal behavior, housing was constructed to support the ECO PuCk ${ }^{\mathrm{TM}}$ with the SPLASH10 satellite transmitter, resulting in the AM-A320A-AU Fluorometer $(458 \mathrm{~g}, 11.9 \times 5.8 \times 6.2 \mathrm{~cm})$. This instrument was deployed on a Steller sea lion (Eumetopias jubatus) captured at Adak, Alaska, on 9 October 2014. For 3 weeks, 188 messages were transmitted successfully for the first dive exceeding $9.5 \mathrm{~m}$ after the top of the hour and included: (1) the chl-a $(\mu \mathrm{g} / \mathrm{cl}$ ) and temperature $\left({ }^{\circ} \mathrm{C}\right)$ values at $3 \mathrm{~m}$ depth, (2) the maximum chl-a value and the temperature and depth values at which it occurred, (3) the chl- $a$ and temperature values at the maximum dive depth (including the depth value), and (4) the sum of all chl-a values from the surface to the maximum depth of the dive.

Conclusions: Although fluorescence quenching, bio-fouling, and additional calibration of the AM-A320A-AU Fluorometer warrant additional investigation, preliminary data indicated this instrument should be an effective means for providing sub-surface, in situ phytoplankton fluorescence (chl-a) relative to animal ecology.

Keywords: Bering Sea, Chlorophyll-a, Callorhinus ursinus, Eumetopias jubatus, Fluorometer, Northern fur seal, Primary productivity, Satellite telemetry, Steller sea lion, Temperature

\section{Background}

As the magnitude and frequency of climatic events increase in the future [1], alterations in sea ice and

\footnotetext{
*Correspondence: michelle.lander@noaa.gov

${ }^{1}$ National Marine Mammal Laboratory, Alaska Fisheries Science Center, National Marine Fisheries Service, National Oceanic Atmospheric Administration, 7600 Sand Point Way N.E., Seattle, WA 98115, USA Full list of author information is available at the end of the article
}

primary production are expected to have cascading influences on food web dynamics in polar waters [2], with consequential stresses on higher trophic levels, including economically important fish species and marine mammals [3]. To effectively manage these species, therefore, it is necessary to understand their direct response to natural variation in the environment and the 
underlying oceanographic processes influencing ecosystem productivity.

Links among physical processes, phytoplankton biomass, primary productivity, and higher trophic levels are poorly understood in remote areas that are relatively inaccessible and difficult to sample $[4,5]$. For this reason, many researchers rely on satellite remote sensing platforms, which use optical measurements of ocean radiance to derive concentration estimates of biogeochemical variables, including chlorophyll- $a$ (chl- $a$ ), which is the primary photosynthetic pigment in phytoplankton, is proportional to the standing stock of phytoplankton, and often serves as a proxy for primary productivity [6]. Satellite remote sensing is advantageous because it provides oceanographic data at global scales, but extended periods of cloud and/or ice cover can reduce satellite visibility in many areas, making it difficult to capture the dynamic nature of the marine environment at shorter time scales. Additionally, some assumptions regarding the water-leaving radiance spectra for coastal waters are invalid due to atmospheric effects, Rayleigh scatter, fresh water input, particulate matter, mixing, and turbidity [7, 8]. This is a substantial disadvantage of satellite remote sensing platforms because coastal areas contain a diverse assemblage of species and account for $30 \%$ of global primary production [9]. Another drawback of remote sensing satellites is their inability to provide sub-surface data. Although there are alternative means for measuring the vertical structure of in situ phytoplankton properties, traditional sampling methods associated with ship time (e.g., Niskin bottles) tend to miss or underestimate the maxima of small-scale or thin planktonic features [10]. Advances in technology can account for this (e.g., fluorometers on gliders, buoys, and drifters), but they can be spatially and temporally limiting or expensive.

Marine animals tagged with satellite transmitters or other electronic instruments are commonly employed as autonomous ocean profilers to provide information about the water column because their movements presumably reflect the distribution of prey resources influenced by oceanographic processes [11]. Not only have tagged animals been useful for examining their ecology relative to the 3D environment, but they have increased data availability in areas where data have previously been sparse $[11,12]$. For example, pinnipeds serving as lowcost in situ ocean sensing platforms have provided data from most of the Southern Ocean, which have been used to identify hydrographic regions, map major fronts, and calculate sea ice formation rates $[5,13,14]$.

We are only aware of a few studies during which in situ phytoplankton properties were measured by animalborne platforms [15-19]. Teo et al. [15] used depth data and light attenuation profiles from archival instruments on Pacific Bluefin tuna (Thunnus orientalis) to estimate chlorophyll concentrations in the water column, whereas Laidre et al. [16] mounted fluorometers and VHF transmitters to floats and deployed them on bowhead whales (Balaena mysticetus) in Greenland to reconstruct a 3D picture of primary production in the coastal regions of Disko Bay. More recently, Guinet et al. [19] successfully collected 3,388 in situ fluorescence profiles coupled with temperature and salinity measurements from the Antarctic sea ice zone by deploying a novel Argos CTD-fluorescence tag on 23 southern elephant seals (Mirounga leonine), which proceeded to concentrate in the Kerguelen plume. Despite this latest development, however, that tag remains too large for smaller marine vertebrates. Thus, the purpose of this project was to develop a smaller satellite-linked fluorometer.

\section{Methods}

We examined the specifications (e.g., size, weight, power consumption, and electronic interface) of four commercially-available fluorometers, including the Seapoint Chlorophyll Fluorometer (Seapoint Sensors, Inc., Exeter, $\mathrm{NH}$, USA), Cyclops Integrator (Turner Designs, Sunnyvale, CA, USA), Pisces Fluorometer (Pisces Design, La Jolla, CA, USA), and a miniature version of the Environmental Characterization Optics series (ECO Puck ${ }^{\text {TM }}$; WET Labs, Inc., Philomath, OR, USA), and concluded the ECO Puck ${ }^{\mathrm{TM}}$ (http://www.wetlabs.com/products/ eflcombo/pucks.htm) was the smallest instrument that would be compatible with a commercially available satellite transmitter manufactured by Wildlife Computers (Redmond, WA, USA). We decided the SPLASH10 (http://wildlifecomputers.com/our-tags/splash/) would serve as the basic architecture for electronic integration because it has a channel designed to log analog voltages from an external sensor and the ability to archive high resolution data, including depth, temperature, and light levels. This instrument has 1 GB of memory and the controller contains up to eight 12-bit analog-to-digital converters, $512 \mathrm{~KB}$ of low-power static RAM, and $128 \mathrm{~KB}$ of program FLASH memory. This model is also equipped with a real-time clock and a wet/dry sensor, which conserves battery power by limiting transmissions to when the animal surfaces.

For initial data exploration during laboratory and field trials an archival TDR10 equipped with a temperature probe was first interfaced with the ECO Puck ${ }^{\text {TM }}$ and configured to measure chl- $a$ ( 0 to $75 \pm 0.02 \mu \mathrm{g}$ $\mathrm{Chl} / \mathrm{L}$ ) at $4 \mathrm{~Hz}$. To determine if this interfaced prototype functioned properly it was suspended with a calibrated Combo Fluorometer-Turbidity Unit (FLNTU; WET Labs) of similar configuration in a black bucket of distilled water, which was diluted in $20 \mathrm{~mL}$ increments 
with a chlorophyll mixture extracted from frozen spinach. Data from the FLNTU were decoded using ECOView software (WET Labs), whereas all voltage readings from the prototype were downloaded, decoded using a data analysis program (DAP; Wildlife Computers), and converted to chl- $a$ using the algorithm from the characterization sheet supplied by WET Labs after a transfer function (gains/offsets provided by Wildlife Computers) was applied to the raw data. Chlorophyll- $a$ values were averaged per dilution period for each instrument, plotted, examined for proper saturation, and tested for linearity using linear regression $(\alpha=0.05)$. An analysis of covariance (ANCOVA; $\alpha=0.05$ ) was also used to determine if linear models differed between the two instruments.

To further verify functionality of the prototype, manual casts of both instruments were conducted at two locations in Hood Canal, Washington. Both instruments were mounted to a metal block (separating them by $\sim 15 \mathrm{~cm}$ ) attached to an $8 \mathrm{~m}$ cable (SOOW 600 VAC Service Cord; McMaster-Carr, Los Angeles, CA, USA), which was suspended at different depths (range 1-6 $\mathrm{m}$ ) for 5 min intervals. Data were processed using methods above, chl- $a$ values were averaged for each depth per instrument, and an analysis of variance (ANOVA) was used to determine if trends differed between the two instruments by examining the interaction term depth $\times$ instrument $(\alpha=0.05)$.

To determine if sensor orientation or animal behavior affected chl- $a$ measurements, the archival prototype was deployed on three trained, open-water Steller sea lions (Eumetopias jubatus) at the Open Water Research Facility, University of British Columbia (UBC). This also allowed us to observe if the sea lions were affected by the fluorometer's LED. Experiments lasted $\sim 50 \mathrm{~min}$, during which an individual sea lion made two to three trips to depth (11.5-12 $\mathrm{m})$ to feed and was filmed with an underwater camera system. Otherwise, the sea lion remained at the surface within a floating Plexiglas dome while respirations were monitored. The instrument was attached to the harness of the first animal with the optics facing forward (towards the head of the sea lion), whereas the optics faced backwards for the second animal. For the third animal, the instrument was also backwards and the animal was released from a boat into the waters off Port Moody and instructed to swim beside the boat for $\sim 20 \mathrm{~min}$ at $2-3.5$ knots. After completing the openwater trials, the data were inspected using Instrument Helper (3.0; Wildlife Computers), a data visualization and analysis program.

After the open-water trials indicated the archival prototype was robust to behaviors of concern (e.g., pitch/ roll, fast speeds, rapid surfacings, etc.), it was completely cast in epoxy ( $370 \mathrm{~g} ; 10.8 \times 6.4 \times 6.2 \mathrm{~cm})$. To collect in situ data on a marine mammal while in its natural habitat, the cast prototype was deployed on a free-ranging, adult female northern fur seal (Callorhinus ursinus) that was captured using a hoop net (Fuhrman Diversified, Seabrook, TX, USA) on 9 September 2013 at Reef Rookery, St. Paul Island, Alaska. The fur seal was manually restrained, weighed to the nearest $0.1 \mathrm{~kg}$ (Dyna-Link, Measurement Systems International, Seattle, WA, USA), and the prototype attached to the dorsal pelage between the scapulae using 5-min epoxy (Devcon Products, Riviera Beach, FL, USA). Additionally, a satellite transmitter (SPOT5, Wildlife Computers) and VHF transmitter (Advanced Telemetry Systems, Isanti, MN, USA) were glued to the lower back to monitor the animal while at sea and on shore, respectively.

After the fur seal returned to the rookery on 18 September 2013, she was located via her VHF transmitter, captured, weighed, and the archival prototype retrieved. Data were downloaded, decoded, and smoothed using a median-value filter; chl- $a$ and temperature outliers (i.e., values $\pm 0.1 \mu \mathrm{g} / \mathrm{L}$ or ${ }^{\circ} \mathrm{C}$ from the median) were replaced with the median using a moving window of 20 values, whereas depth outliers (i.e., values $\pm 4 \mathrm{~m}$ from the median) were replaced with the median using a moving window of 10 values. Smoothed data were further inspected using Instrument Helper and IgorPro (WaveMetrics, Portland, OR, USA) and anomalous measurements (i.e. data spikes) were omitted. Smoothed data corresponding to the top of the second were merged with the satellite telemetry data after they were obtained through Service Argos, decoded using DAP, and filtered using a maximum transit rate of $2 \mathrm{~m} / \mathrm{s}$ [20]. The merged data set was then processed with a continuous-time correlated random walk model (CTCRW; [21]) to predict uniformly spaced locations every second so that in situ measurements of chl- $a$ and temperature could be spatially interpolated to locations at sea ( $\mathrm{R} 3.1 .2,[22])$ and examined in a 3D environment (ArcScene 10.1; ESRI, Redlands, CA, USA).

The archived data set also was used to determine the best approach for collecting, summarizing, and compressing data for transmission through the Argos satellite system, which has bandwidth restrictions of 256 bits per message. For data compression we decided fluorescence and temperature data would be collected at $4 \mathrm{~Hz}$ during the ascent of the first dive exceeding a user-defined depth (i.e. $\geq 9.5 \mathrm{~m}$ for this case report and referred to hereafter as a 'qualifying' dive) after the top of each hour. After converting fluorescence to chl- $a$ ( $\mu \mathrm{g} /$ $\mathrm{cL}$ ) on board the instrument (via correction coefficients and scale factors applied to the raw data) transmitted data would be reported to the nearest hour and include: (1) the chl- $a$ and temperature $\left({ }^{\circ} \mathrm{C}\right)$ values at $3 \mathrm{~m}$ depth (for future comparisons with satellite remote sensing 
data), (2) the maximum chl- $a$ value (with corresponding temperature value) and the depth at which they occurred, (3) the chl- $a$ and temperature values at the maximum dive depth (including the depth value), and (4) the sum of all chl- $a$ values from the surface to the maximum depth of the dive. This sampling scheme was chosen to conserve battery power and achieve a twomonth life expectancy for the tag. This technology is customizable to the user, however, and different forms of data compression can be considered. Additionally, data can be relayed in different formats (i.e., raw data vs. chl- $a$ values).

To determine if the data reduction routine established for the Argos system was a sufficient summary of the data, and to verify functionality of the Argos message generation by a transmitting unit, data from the archival prototype were processed with a 'simulator' (i.e., Windows-based software package comprised of the same code installed on the SPLASH10 controller) to produce messages that would be transmitted through Service Argos. Those messages were manually cross-referenced with the archived data set to confirm consistency. A housing was then constructed to support the ECO Puck ${ }^{\mathrm{TM}}$ fluorometer with the SPLASH10 and two independent power sources; the fluorometer was powered by $3 \mathrm{AA}$ batteries, whereas the SPLASH10 controller was powered by $2 \frac{1}{2}$ AA batteries connected in series. After the final tag was assembled (AM-A320A-AU Fluorometer; $458 \mathrm{~g}, 11.9 \times 5.8 \times 6.2 \mathrm{~cm}$; Fig. 1 ) it was placed in a pressure chamber with a voltage standard (WET Labs) and dives to known depths were simulated to further verify functionality of the Argos message generation.

To observe operation of the new AM-A320A-AU Fluorometer in the field it was deployed on a free-ranging, adult female Steller sea lion at Adak, Alaska on 9 October 2014. That animal was chemically immobilized [23], intubated, and supplemented with isoflurane (range $0.5-1.5 \%$ ) in $100 \%$ oxygen using a portable vaporizer to maintain anesthesia while the fluorometer was attached to the dorsum using 5-min epoxy (Devcon). After the transmitter was secure, the sea lion was administered reversal agents, extubated, and monitored before release [23]. After transmissions ceased, data were obtained from Service Argos and chl- $a$ and temperature data were spatially interpolated to locations at sea using Argos positions that were decoded, filtered, and modeled using the same methods detailed for the northern fur seal.

\section{Results}

After interfacing the ECO Puck ${ }^{\mathrm{TM}}$ with the TDR10, laboratory trials with the chlorophyll solution indicated measurements of chl- $a$ concentration were linear $\left(F=443.163, P=7.490 \mathrm{E}^{-7}\right)$, saturated at the

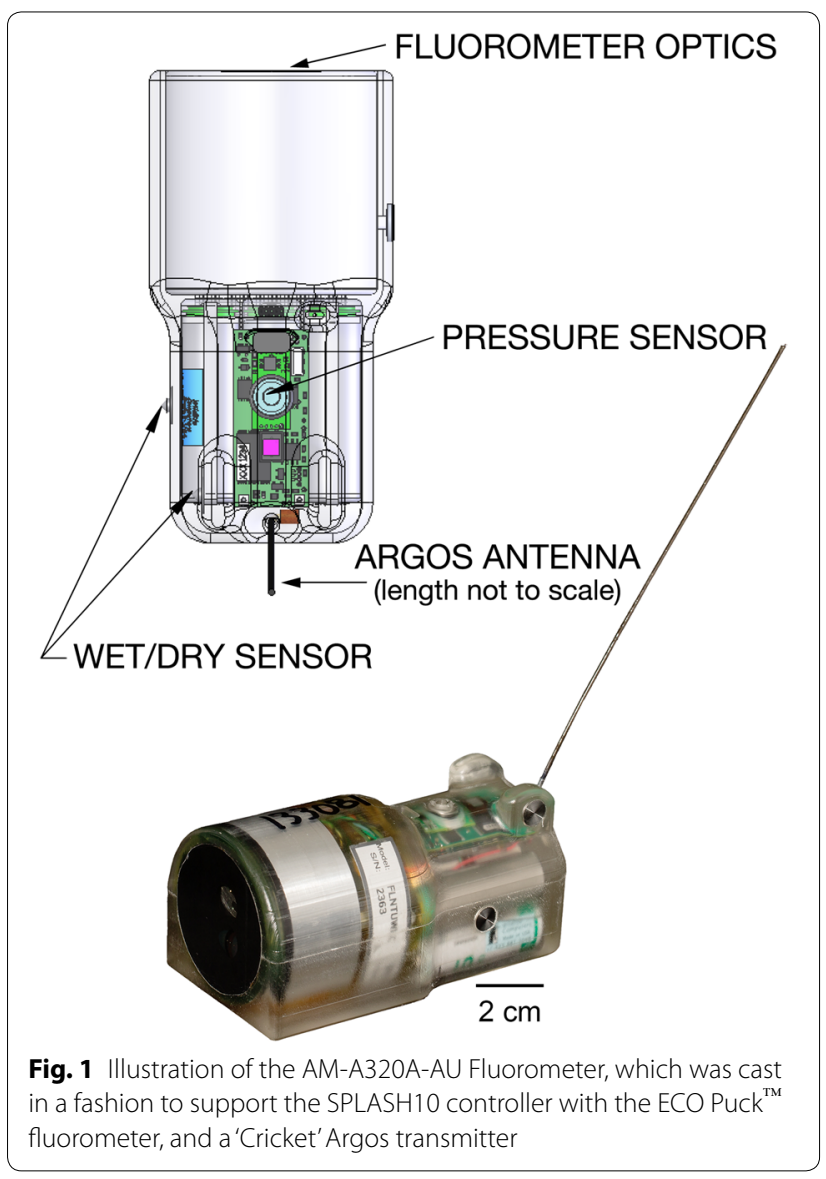

programmed maximum value (i.e. $73.9 \mu \mathrm{g} \mathrm{Chl} / \mathrm{L}$ ), and did not differ significantly from measurements collected by the calibrated FLNTU (slopes $F=0.158, P=0.705$; intercepts $F=0.759, P=0.413)$. Furthermore, results from the manual casts in Hood Canal also indicated data from the prototype were comparable to the FLNTU. Mean chl- $a$ values of the two instruments varied together with depth $(F=0.151, P=0.7030)$ suggesting integrity of the ECO Puck ${ }^{\mathrm{TM}}$ was maintained.

Inspection of the chl- $a$ data collected using the openwater Steller sea lions revealed some spikes when the fluorometer turned off, but overall, orientation of the fluorometer did not appear to affect the data. For example, chl- $a$ readings for the first trip to depth within the feeding cage were similar between the first $(\bar{x}=1.09 \mu \mathrm{g} / \mathrm{L}, \mathrm{SD}=0.19, n=744$ measurements $)$ and second $(\bar{x}=1.06 \mu \mathrm{g} / \mathrm{L}, \mathrm{SD}=0.24, n=786$ measurements) sea lions, which had the prototype oriented in opposite directions. Furthermore, few anomalous readings were collected by the third sea lion while free-swimming outside the cage. Lastly, the sea lions did not appear disturbed by the blue light emitted from the instrument. Given our limited sample size, however, we decided the 
sensor should be oriented in the final tagware such that it would face towards the rear of the animal.

Similar to data collected by the open-water sea lions, the archived data record of the free-ranging northern fur seal revealed some spikes in the chl- $a$ data when the fluorometer powered down and some spikes in the depth data, which were likely a result of the SPOT5 satellite transmitter attached to the animal (archival instruments will pick up the electromagnetic energy emitted from a nearby satellite transmitter, providing false readings in the depth channels). Eliminating those anomalies and smoothing the data resulted in 87,053 chl-a and temperature measurements collected at the top of the second for use in the CTCRW model. Overall, chl- $a$ $(\bar{x}=1.24 \mu \mathrm{g} / \mathrm{L}, \mathrm{SD}=0.93$, range $0.02-8.70)$ was detected in depths $\leq 40 \mathrm{~m}$ during a large looping trip of $\sim 865 \mathrm{~km}$ to the outer domain shelf of the Bering Sea that lasted 8 days (Fig. 2). Sub-surface chl- $a$ maxima (SCMs) primarily occurred just northwest of St. Paul Island (Fig. 2) in cooler surface waters (Fig. 3). For the first half of the trip, most qualifying dives were as deep as the thermocline, whereas many qualifying dives exceeded the thermocline during the second half of the trip (Fig. 3).

The Steller sea lion tagged with the AM-A320A-AU Fluorometer was tracked for 21 days from 9 to 30 October 2014, during which time 188 messages $(\bar{x}=9$ messages/day, $\mathrm{SD}=3$, range $1-17)$ containing chl- $a$ and temperature data and 278 Argos positions were received in 304 satellite passes (Fig. 4). That animal remained in Adak Strait for the duration of tag longevity, diving to depths that ranged from 2.5 to $135 \mathrm{~m}(\bar{x}=24.9, \mathrm{SD}=1.5$, $n=188$ dives). The majority of those dives (93\%) contained SCMs that ranged from 0.52 to $49.24 \mu \mathrm{g} / \mathrm{L}$ $(\bar{x}=2.84, \mathrm{SD}=7.74)$ within $42 \mathrm{~m}$ of the surface $(\bar{x}$ depth of $\mathrm{SCMs}=7.8 \mathrm{~m}, \mathrm{SD}=8.1$; Fig. 4 ).

\section{Discussion}

A satellite-linked fluorometer (AM-A320A-AU Fluorometer) was assembled for marine animals and preliminary data indicated it was an effective tool for collecting in situ phytoplankton fluorescence. Although the instrument is smaller than others currently available, we recommend that it be deployed on the back or between the shoulders of larger animals given the size. For example, the size of the archival prototype, which was similar to the final product, appeared suitable for the open-water Steller sea lions, whereas this may not have been the case for the adult female northern fur seal that was tagged on Reef Rookery at St. Paul. That animal weighed $\sim 36.8 \mathrm{~kg}$ when tagged and $\sim 35.4 \mathrm{~kg}$ when recaptured after an 8 day trip to sea (albeit mass estimates may be biased because the animal never settled down in the net while being weighed). Although trip duration and mass change were within ranges reported for other lactating northern fur seals from Reef Rookery [24], the potential impact of longer tag deployments on northern fur seals or animals of similar or smaller size warrants further consideration.

Fluorescence quenching, bio-fouling, and additional calibration of the AM-A320A-AU Fluorometer also warrant additional investigation. Daytime fluorescence quenching (i.e., reduction in the fluorescence quantum yield observed during periods of high irradiance in daylight hours) appears to be a global phenomenon [25]. During this study, chl- $a$ measurements collected by the archival prototype on the northern fur seal were variable throughout the day. The distribution of chl- $a$ data averaged for hourly bins indicated greater concentrations of chl- $a$ were measured from sunset to sunrise (22:00-9:00 local time) than from sunrise to sunset, and that difference was even more apparent within the first $10 \mathrm{~m}$ of the surface (data not shown). Fluorescence quenching likely occurred, therefore, but nocturnal measurements of chl- $a$ comprised the majority ( $85 \%$ ) of the data set so quenching was not a concern. Likewise, nocturnal (20:00-9:00 local time) measurements of chl- $a$ comprised the majority ( $87 \%$ ) of data collected by the satellite-linked fluorometer on the Steller sea lion. Although some oceanographers only use nocturnal measurements to minimize effects of photoquenching [26], this is not an option for those interested in examining animal behavior relative to the environment throughout the day and some methods have been established to correct for quenching $[18,19,25,27]$. For example, Sackmann et al. [25] used optical backscattering coupled with fluorescence measurements to characterize quenching in Northeast Pacific waters. Unfortunately, other satellite-linked fluorometers that are currently available for marine animal applications are comprised of a single tube fluorometer, which is not capable of containing additional sensors, whereas additional configurations of the ECO Puck ${ }^{\mathrm{TM}}$ are available (e.g., FLBB), allowing for simultaneous scattering and fluorescence sensors without increasing the size of the instrument. It is also possible to re-calibrate existing channels (i.e., provide back scatter calibration to the turbidity channel) on the ECO Puck ${ }^{\mathrm{TM}}$ to reduce costs.

Bio-fouling also was not addressed for the AM-A320AAU Fluorometer, but we did not expect this would be an issue given a projected life span of 2 months. Guinet et al. [19] found the optics of eight fluorometers were clean after being deployed on southern elephant seals for 3 to 8 months. They speculated bio-fouling did not occur because seals spent limited time in the euphotic zone and more time in greater depths of lower temperatures. Similarly, little to no bio-fouling was observed for fluorometers deployed on some sea gliders, which also tend to remain below the euphotic zone and cycle through 

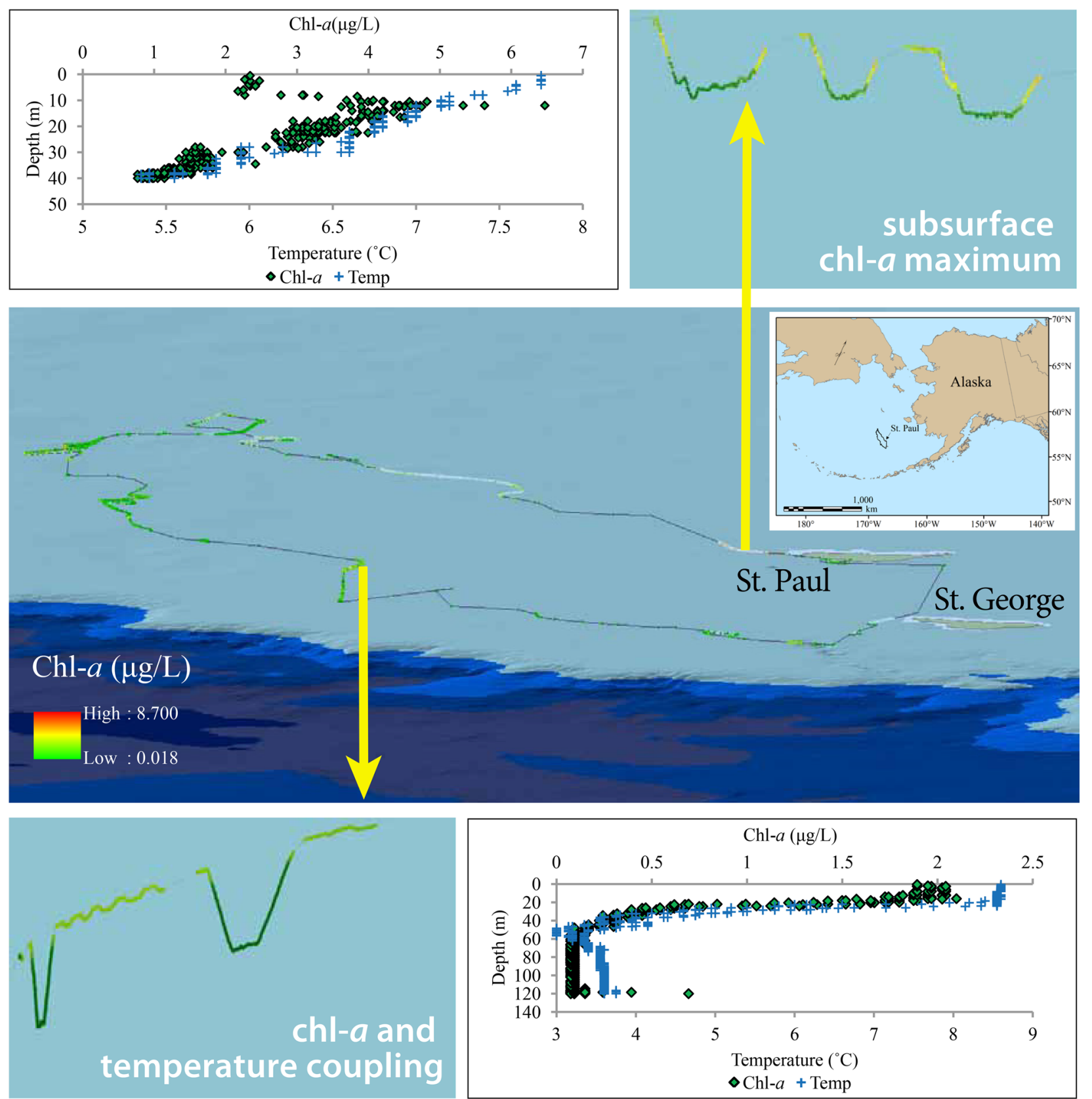

Fig. 2 Three-dimensional illustration of chlorophyll- $a(\mathrm{chl}-a)$ values ( $\mu \mathrm{g} / \mathrm{L})$ for predicted locations obtained from the CTCRW model for a northern fur seal Callorhinus ursinus captured and tagged on St. Paul Island, Alaska. Examples of chl- $a$ and temperature $\left({ }^{\circ} \mathrm{C}\right)$ profiles correspond to adjacent dives indicated by yellow arrows

a pressure range that few organisms can tolerate [28]. However, bio-fouling may pose a problem for shallowdiving species that do not haul-out and this should be considered in the future.

Although laboratory evaluations of environmental sensors are essential for determining accuracy of stated performance by manufacturers [29], the ECO
Puck $^{\mathrm{TM}}$ was not calibrated beyond that conducted by WET Labs. The scale factors provided by WET Labs were determined using the absorption method with a mono-culture of phytoplankton Thalassiosira weissflogii, but environmental conditions as well as cell morphology, physiological status, and community composition of phytoplankton all affect the relationship between 

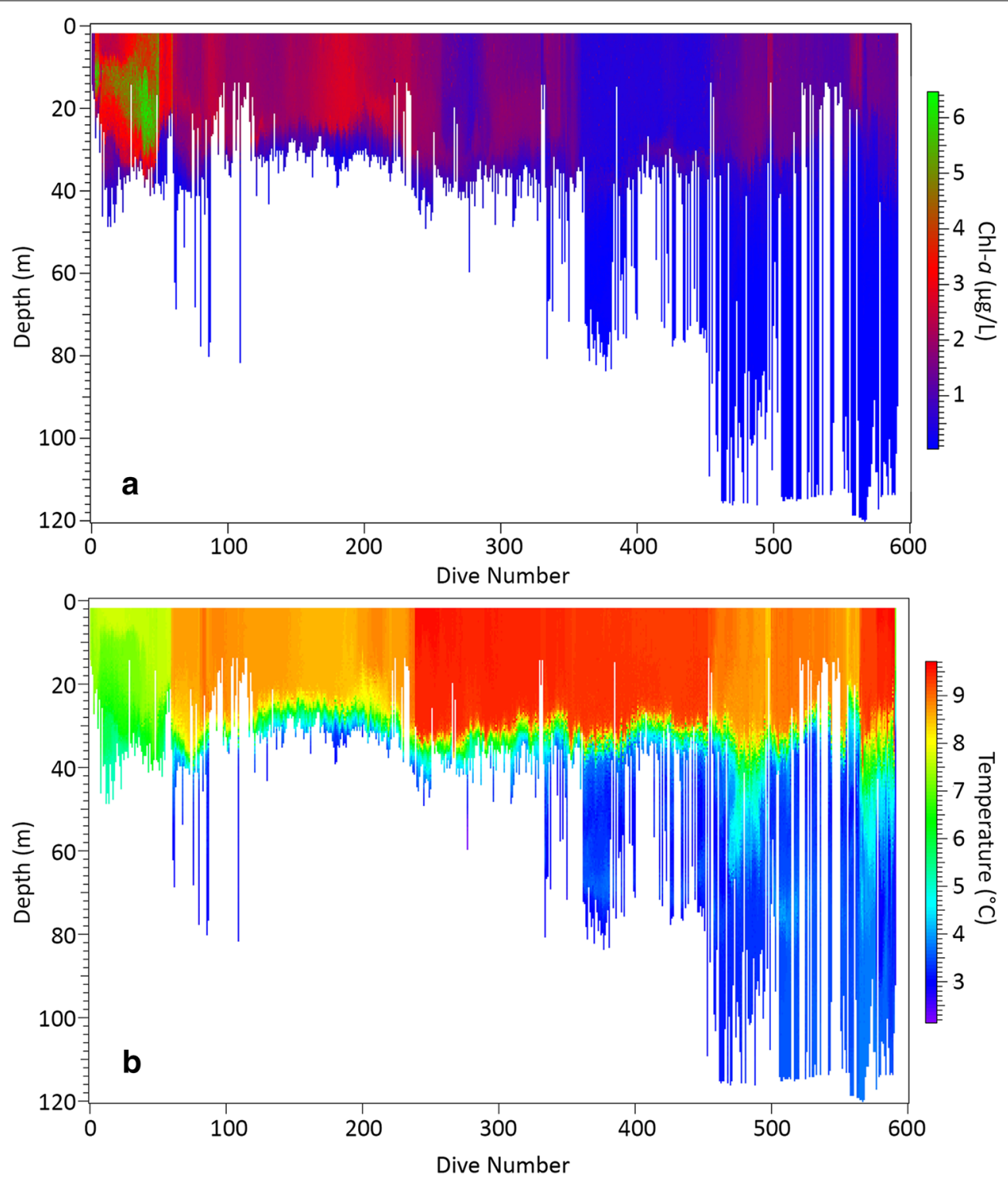

Fig. 3 Chlorophyll- $a(\mathrm{chl}-a ; \mu \mathrm{g} / \mathrm{L} ; \mathbf{a})$ and temperature $\left({ }^{\circ} \mathrm{C} ; \mathbf{b}\right)$ profiles of qualifying dives $(>9.5 \mathrm{~m})$ conducted by an adult female northern fur seal Callorhinus ursinus captured on St. Paul Island and tagged with the archival fluorometer prototype

fluorescence and concentrations of chl- $a$ [30]. Furthermore, other plant pigments, degradation products, and dissolved organic matter can interfere with light absorption or change the optical path of fluoresced light [30]. Thus, when feasible, measurements of discreet samples of phytoplankton populations in the area of instrument deployment should be collected.

\section{Conclusions}

Despite the diverse constraints of fluorometers, in situ fluorescence supplies valuable information on the relative bulk properties, magnitude, and temporal/spatial distribution of chl- $a$ concentrations in the water column [30] and this project provided a glimpse of the capabilities of a fluorometer deployed on a marine mammal. Both the archival and satellite-linked instruments provided a substantial amount of chl- $a$ and temperature profiles for a fairly broad area over a short period of time. These data were useful for identifying areas of chl-a/temperature coupling, potential fronts, and SCMs, which significantly contribute to primary production [31], are an important location for predator-prey interactions [32], can possibly indicate areas of pelagic-benthic coupling [33], and are necessary for primary productivity algorithms [34]. 


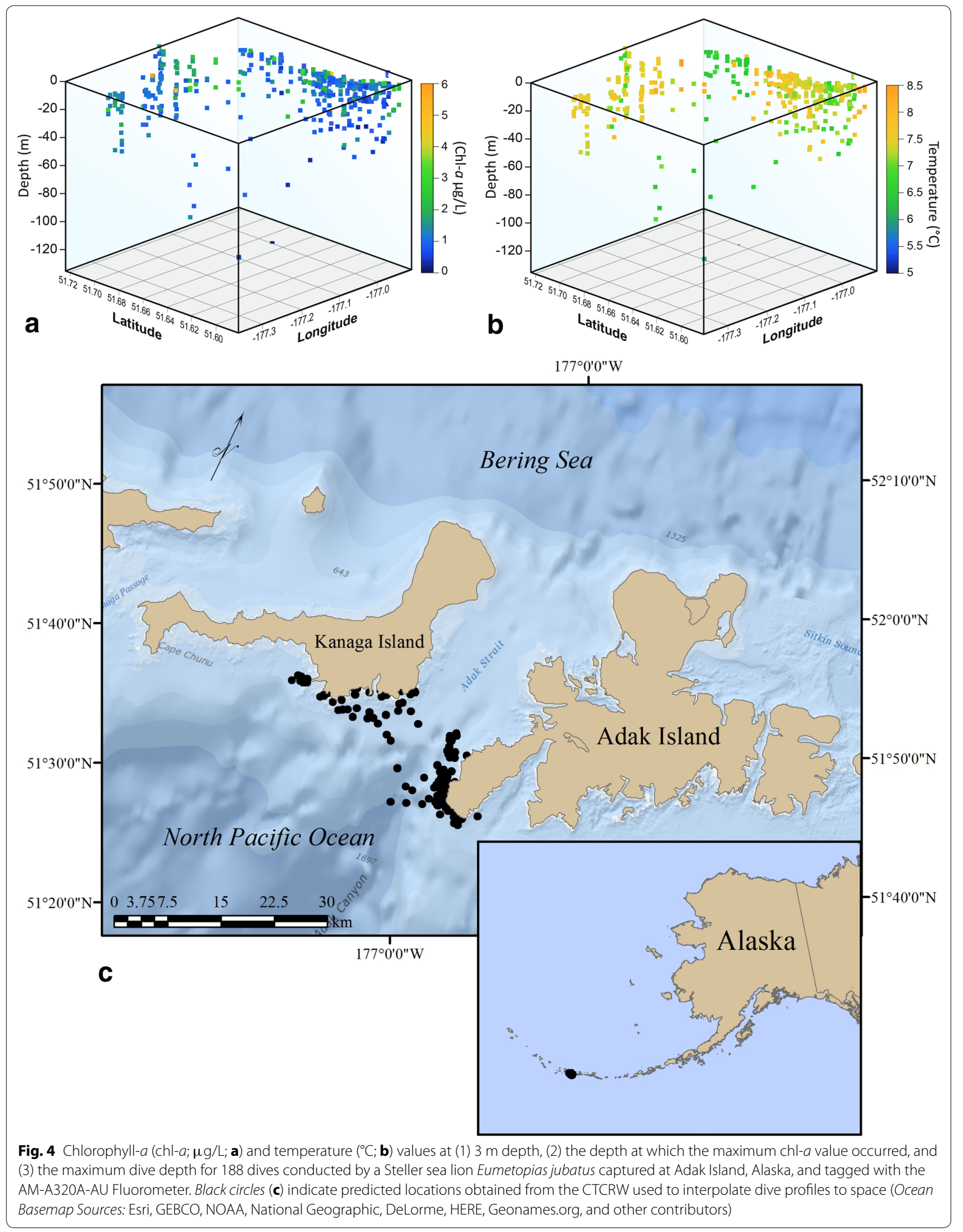


A considerable amount of effort has traditionally been needed to study these features, but animal-borne fluorometers will greatly improve the pace and efficiency of data collection while providing a greater understanding of how animals respond to their environment.

\section{Abbreviations}

chl-a: chlorophyll-a; CTCRW: Continuous-time correlated random walk; SCM: Subsurface chlorophyll maxima; FLNTU: Fluorometer-Turbidity Unit.

\section{Authors' contributions}

MEL conducted all field work, summarized the data, wrote the manuscript, and assisted TL with the conceptual design. TL researched commercially available fluorometers, integrated the chosen fluorometer with the controller, and was responsible for project management. MR was responsible for algorithm design, system testing, and data interpretation. AF conducted software implementation and hardware design, and $\mathrm{MH}$ assisted with project coordination. All authors read and approved the final manuscript.

\section{Author details}

${ }^{1}$ National Marine Mammal Laboratory, Alaska Fisheries Science Center, National Marine Fisheries Service, National Oceanic Atmospheric Administration, 7600 Sand Point Way N.E., Seattle, WA 98115, USA. ${ }^{2}$ Wildlife Computers, 8345 154th Ave N.E., Redmond, WA 98052, USA.

\section{Acknowledgements}

We thank the Oceanography Department of the University of Washington (G. Brusseau, A. Devol, M. Logsdon, N. Pelland, W. Ruef, and G. Theussen), the Open Water Research Facility at UBC (T. Neale, R. Barrick, R. Brandon, D. Rosen, and A. Trites), the Alaska Ecosystems Program (T. Gelatt, R. Ream, and J. Sterling) and Polar Ecosystems Program (P. Boveng, M. Cameron, S. Dahl, J. Jansen, J. London, and H. Ziel) at the National Marine Mammal Laboratory, and J. Baker, M. Donohue, G. Larsen, and M. Barbieri for all of their assistance and support during this project. K. McKinney and R. White (Alaska Fisheries Science Center) kindly provided assistance with photography and graphics and B. Fadely, T. Gelatt, J. Lee, J. London, D. Costa, and two anonymous reviewers provided constructive comments on the manuscript. This work was supported by the National Cooperative Research Program of the National Oceanic and Atmospheric Administration and the North Pacific Research Board (NPRB publication number 567). Fur seal research was conducted under permit $\# 14327$. The use of trade, product, or firm names is for descriptive purposes only and does not imply endorsement by the US Government. The findings and conclusions in the paper are those of the authors and do not necessarily represent the views of the National Marine Fisheries Service.

\section{Compliance with ethical guidelines}

\section{Competing interests}

The authors declare that they have no competing interests.

Received: 2 February 2015 Accepted: 9 September 2015

Published online: 02 October 2015

\section{References}

1. IPCC [Intergovernmental Panel on Climate Change]. Climate change 2007: the physical science basis. Geneva: Intergovernmental Panel on Climate Change Secretariat; 2007.

2. Smetacek $V$, Nicol S. Polar ocean ecosystems in a changing world. Nature. 2005;437:362-8

3. Grebmeier JM, Overland J, Moore SE, Farley EV, Carmack EC, Cooper LW, Frey KE, Helle JH, McLaughlin FA, McNutt SL. A major ecosystem shift in the northern Bering Sea. Science. 2006;311:1461-4.

4. Trites AW, Miller AJ, Maschner HDG, Alexander MA, Bograd SJ, Calder JA, et al. Bottom-up forcing and the decline of Steller sea lions (Eumetopias jubatus) in Alaska: assessing the ocean climate hypothesis. Fish Oceanogr. 2007;16:46-67.
5. Charrassin JB, Hindell M, Rintoul SR, Roquet F, Sokolov S, Biuw M, et al. Southern Ocean frontal structure and sea-ice formation rates revealed by elephant seals. Proc Natl Acad Sci USA. 2008;105:11634-9.

6. Martin S. An introduction to ocean remote sensing. New York: Cambridge University Press; 2004.

7. Ruddick KG, Ovidio F, Rijkeboer M. Atmospheric correction of SeaWIFS imagery for turbid coastal and inland waters. Appl Opt. 2000;39:897-912.

8. Carder KL, Chen FR, Cannizzaro JP, Campbell JW, Mitchell BG. Performance of MODIS semi-analytic ocean color algorithm for chlorophyll-a. Adv Space Res. 2004;33:1152-9.

9. Wollast R. Evaluation and comparison of the global carbon cycle in the coastal zone and in the open ocean. In: Brink KH, Robinson AR, editors. The sea, the global coastal ocean: processes and methods. New York: Wiley; 1998. p. 213-52.

10. Donaghay $P L$, Rines HM, Sieburth J. Simultaneous sampling of fine scale biological, chemical and physical structure in stratified waters. Ergeb Limnol. 1992;36:97-108.

11. Boehlert GW, Costa DP, Crocker DE, Green P, O'Brien T, Levitus S. LeBoeuf: autonomous pinniped environmental samples: using instrumented animals as oceanographic data collectors. J Atmos Ocean Technol. 2001;18:1882-93.

12. Block BA, Costa DP, Boehlert GW, Kochevar RE. Revealing pelagic habitat use: the tagging of Pacific pelagics program. Oceanol Acta. 2003;25:255-66.

13. Biuw M, Boehme L, Guinet C, Hindell M, Costa D, Charrassin JB, et al. Variations in behavior and condition of a Southern Ocean top predator in relation to in situ oceanographic conditions. Proc Natl Acad Sci. 2007;104:13705-10.

14. Costa DP, Klinck JM, Hofman EE, Dinniman MS, Burns JM. Upper ocean variability in west Antarctic Peninsula continental shelf waters as measured using instrumented seals. Deep-Sea Res II. 2008;55:323-37.

15. Teo SLH, Kudela RM, Rais A, Perle C, Costa DP, Block BA. Estimating chlorophyll profiles from electronic tags deployed on pelagic animals. Aquat Biol. 2009;5:195-207.

16. Laidre KL, Heide-Jørgensen MP, Logsdon ML, Delwiche L, Nielsen TG. A whale of an opportunity: examining the vertical structure of chlorophyll$a$ in high Arctic waters using instrumented marine predators. Mar Biol Res. 2010;6:519-29.

17. Jaud T, Dragon AC, Garcia JV, Guinet C. Relationship between chlorophyll a concentration, light attenuation, and diving depth of the southern elephant seal Mirounga leonine. PLoS One. 2012;7:e47444. doi:10.1371/ journal.pone.0047444.

18. Xing X, Claustre H, Blain S, D'Ortenzio F, Antoine D, Ras J, Guinet C. Quenching correction for in vivo chlorophyll fluorescence acquired by autonomous platforms: a case study with instrumented elephant seals in the Kerguelen region (Southern Ocean). Limnol Oceanogr Methods. 2012;10:483-95.

19. Guinet C, Xing X, Walker E, Monestiez P, Marchand S, Picard B, et al. Calibration procedures and first dataset of Southern Ocean chlorophyll a profiles collected by elephant seals equipped with a newly developed CTD-fluorescence tags. Earth Syst Sci Data. 2013;5:15-29. doi:10.5194/ essd-5-15-2013.

20. McConnell BJ, Chambers C, Fedak MA. Foraging ecology of southern elephant seals in relation to the bathymetry and productivity of the Southern Ocean. Antarct Sci. 1992;4:393-8.

21. Johnson DS, London JM, Lea M, Durban JW. Continuous-time correlated random walk model for animal telemetry data. Ecology. 2008;89:1208-15.

22. R Development Core Team. R: a language and environment for statistical computing. R Foundation for Statistical Computing, Vienna, Austria; 2014. ISBN 3-900051-07-0. http://www.R-project.org.

23. Haulena M. Otariid Seals. In: West G, Heard D, Caulkett N, editors. Zoo animal and wildlife immobilization and anesthesia. 2nd ed. Ames: Wiley; 2014. p. 661-72.

24. Call KA, Ream RR, Johnson D, Sterling JT, Towell RG. Foraging route tactics and site fidelity of adult female northern fur seal (Callorhinus ursinus) around the Pribilof Islands. Deep Sea Res II. 2008:55:1883-96.

25. Sackmann BS, Perry MJ, Eriksen CC. Seaglider observations of variability in daytime fluorescence quenching of chlorophyll- $a$ in Northeastern Pacific coastal waters. Biosci Discuss. 2008;5:2839-65. 
26. Perry MJ, Sackmann BS, Eriksen CC, Lee CM. Seaglider observations of blooms and subsurface chlorophyll maxima off the Washington coast. Limnol Oceanogr. 2008;53:2169-79.

27. Biermann L, Guinet C, Bester M, Brierley A, Boehme L. An optimized method for correcting quenched fluorescence yield. Ocean Sci Disc 2014;11:1243-64

28. Sackmann BS. Remote assessment of 4-D phytoplankton distributions off the Washington coast. PhD Thesis, University of Maine. 2007.

29. Mowlem M, Hartman S, Harrison S, Larkin KE. Intercomparison of biogeochemical sensors at ocean observatories. Southampton: National Oceanographic Center; 2008.

30. Suggett DJ, Maclntyre HL, Geider RJ. Evaluation of biophysical and optical determinations of light absorption by photosystem II in phytoplankton. Limnol Oceanogr Methods. 2004;2:316-32.

31. Ardyna M, Babin M, Gosselin M, Devred E, Bélanger S, Matsuoka A, Tremblay JE. Parameterization of vertical chlorophyll $a$ in the Arctic
Ocean: impact of the subsurface chlorophyll maximum on regional, seasonal and annual primary production estimates. Biogeosci Discuss. 2013;10:1345-99.

32. Scott BE, Sharples J, Ross ON, Wang J, Pierce GJ, Camphuysen CJ. Subsurface hotspots in shallow seas: fine-scale limited locations of top predato foraging habitat indicated by tidal mixing and subsurface chlorophyll. Mar Ecol Prog Ser. 2010;408:207-26.

33. Martin J, Tremblay JE, Gagnon J, Tremblay G, Lapoussière A, Jose C, et al. Prevalence, structure and properties of subsurface chlorophyll maxima in Canadian Arctic. Mar Ecol Prog Ser. 2010;412:69-84.

34. Arrigo KR, van Dijken G, Pabi S. Impact of a shrinking Arctic ice cover on marine primary production. Geophys Res Lett. 2008;. doi:10.1029/200 8GL035028.
Submit your next manuscript to BioMed Central and take full advantage of:

- Convenient online submission

- Thorough peer review

- No space constraints or color figure charges

- Immediate publication on acceptance

- Inclusion in PubMed, CAS, Scopus and Google Scholar

- Research which is freely available for redistribution

Submit your manuscript at www.biomedcentral.com/submit 